\section{A blot on the land}

\section{William E. Rees}

$\mathrm{H}$ ow many people lie awake at night pondering: "Just how much of the planet is dedicated to supporting me in the style to which I am accustomed?" This is - or should be - the first question of human ecology, yet very few people have given it a moment's thought. It seems that modern humans, particularly the growing proportion of urbanites, are committed dualists. People today are so psychologically alienated from nature that they rarely think of themselves as biological entities, let alone as dependent components of the world's ecosystems.

This is no trivial cognitivelapse. In 1992 the Union of Concerned Scientists warned that "a great change in our stewardship of the Earth and the life on it is required if vast human misery is to be avoided and our global home on this planet is not to be irretrievably mutilated". The world is facing an ecological crisis, yet most people have only the shallowest understanding of their own species' role as causative agent. True, everyone has something to say about climate change, biodiversity loss or some other so-called 'environmental problem', but the latter term effectively externalizes the issue (dualism again), drawing our attention from the cause to mere symptoms of the crisis. It is not just the 'environment' that needs to be fixed, but humans ourselves - the environmental crisis is the product of gross human ecological dysfunction (or, if you prefer, of humanity's spectacular evolutionary success).

One concept that seems to be effective in bringing this reality home is 'ecological footprint' analysis. Eco-footprinting actually answers the question with which this essay opens. It grabs attention because it focuses on personal consumption and translates it into a corresponding land area — something

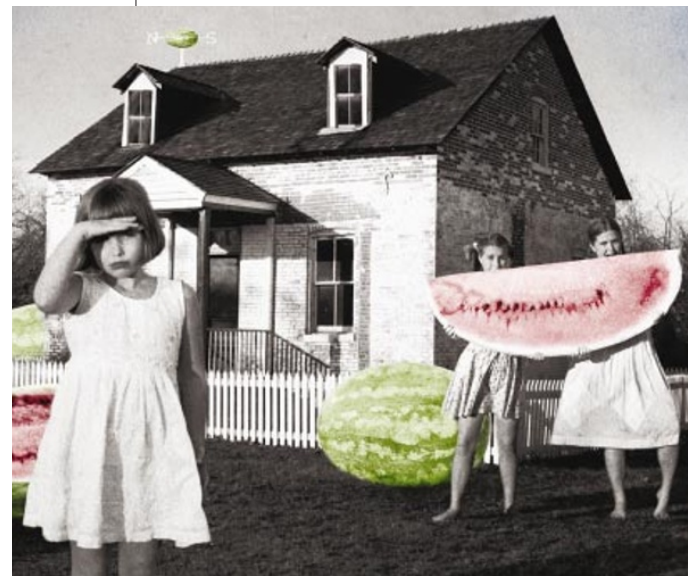

Bigger is not better: people need to realize that their current consumption cannot be sustained. else that ordinary citizens can understand.

I originally proposed ecological footprinting to counter economists' arguments that the concept of carrying capacity is irrelevant to human beings. Conventional carrying capacity is defined as the population of a given species that could be supported indefinitely by a specified habitat. However, economists argue that trade and improved resource productivity can raise the carrying capacity of a region indefinitely, thus rendering the concept meaningless for humans. Eco-footprint analysis subverts this argument simply by inverting the carrying-capacity ratio. Instead of asking how many people a particular area might support, we ask what area is required to support a particular population. Thus, the eco-footprint of a defined population is the area of productive ecosystems that is required on a continuous basis to produce the resources that the population consumes and to assimilate its waste. As the relevant land and water can be located anywhere, the method incorporates land and water areas appropriated through trade and natural flows, and automatically reflects prevailing technology.

The results of eco-footprint analysis are often startling, despite the fact that its basic method and assumptions are quite conservative. The Living Planet Report 2002 shows that the average eco-footprints of residents of high-income countries range from almost five to over ten hectares, whereas the poorest of the poor live on less than half a hectare. Many high-income or densely populated countries have an ecological deficit that is several times larger than their domestic productive land/waterscapes. They survive on imports and by imposing on the global commons. Perhaps most disturbing is the fact that the world's average human eco-footprint is about $2.3 \mathrm{ha}$, even though there are only 1.9 ha of productive land and water per person on Earth. The human enterprise is already overshooting the global carrying capacity, funding further expansion by liquidating 'its' natural capital.

This situation is potentially catastrophic. Both the ecosphere and the human economy are self-organizing, dissipative structures that are far from (thermodynamic) equilibrium. This means that they grow and increase their internal order by importing available energy from their host systems and by dissipating their wastes back to their hosts. The problem is that whereas the ecosphere evolves by dissipating solar energy, the human enterprise grows by dissipating the ecosphere. Humans are consuming the ecosphere's wealth faster than the ecosphere can renew itself. We are now the dominant macro-consumer in all of the world's major ecosystem types, a paradoxical situation for a species that considers itself

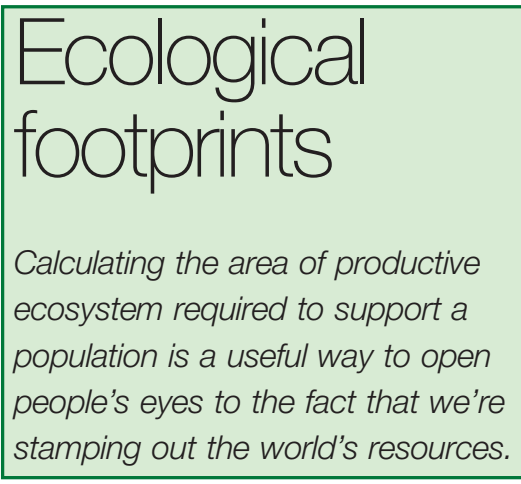

to have cut its ties with nature. The evidence is all around us: deforestation, species loss, landscape degradation, falling water tables and climate change.

What has brought us to this dangerous juncture? The driving forces are both biological and cultural, unconscious and overt. First, Homo sapiens is behaviourally predisposed to expand into all available ecological space and to consume to the level allowed by contemporary technology. Technology advances relentlessly, but evolution has provided humans with no inhibition against destroying their habitats. Second, humans remain a myth-bound species that is capable of astonishing feats of self-delusion. The dominant cultural myth today promotes a materialists' vision of global 'development', characterized by unlimited economic expansion and fuelled by open markets and more liberalized trade. This myth reinforces our already dangerous expansionist tendencies.

The general problem is apparently an ancient one. In 1995 Joseph Tainter wrote: "What is perhaps most intriguing in the evolution of human societies is the regularity with which the pattern of increasing complexity is interrupted by collapse..." Humanity is once again on a collision course with biophysical reality — this time on a global scale — and as biology provides no immediate remedy, the solution must be cultural. The eco-footprint challenge for both the natural and social sciences in the twenty-first century is to engineer the means by which human beings can live peaceful, comfortable and satisfying lives on the biological life-support provided by less than two hectares per capita ( 1.3 ha by 2050 ), while taking into account the needs of other species. The alternative is resource wars and descent into geopolitical chaos.

William E. Rees is at the School of Community and Regional Planning, University of British Columbia, 6333 Memorial Road, Vancouver, British Columbia V6T 1Z2, Canada.

\section{SELECTED READINGS}

Tainter, J. Futures 27, 397-407 (1995).

Worldwide Fund for Nature Living Planet Report 2002 (WWF, Gland, Switzerland, 2002).

Rees, W. E. Environ. Urbanization 4, 120-130 (1992).

Rees, W. E. Bull. Sci. Tech. Soc. 22, 249-268 (2002). 